\title{
Pharmacological inhibition of LSD1 activity blocks REST-dependent medulloblastoma cell migration
}

Keri Callegari ${ }^{1,5}$, Shinji Maegawaa ${ }^{1}$, Javiera Bravo-Alegria ${ }^{1}$ and Vidya Gopalakrishnan ${ }^{1,2,3,4,5^{*}}$

\begin{abstract}
Background: Medulloblastoma (MB) is the most common malignant brain tumor in children. Current problems in the clinic include metastasis, recurrence, and treatment-related sequelae that highlight the need for targeted therapies. Epigenetic perturbations are an established hallmark of human MB and expression of Lysine Specific Demethylase 1 (LSD1) is elevated in MBs compared to normal tissue, suggesting that LSD1 inhibitors may have efficacy against human MB tumors.

Methods: Expression of LSD1 was examined across a publicly-available database and correlated with patient outcomes. Sonic Hedgehog (SHH) MB samples were clustered based on expression of LSD1 and LSD1-associated $R E-1$ silencing transcription factor (REST) target genes as well as genes involved in metastasis. Resulting clusters were examined for patient outcomes associated with LSD1 and REST expression. Human SHH MB cell lines were transduced with a REST-transgene to create isogenic cell pairs. In vitro viability and cell migration assays were used to examine the effect of LSD1 knockdown or inhibition on these parameters.
\end{abstract}

Results: We demonstrate that subsets of SHH MB tumors have elevated LSD1 expression coincident with increased expression of its deubiquitylase, USP7, and REST. Patients with co-elevation of USP7, REST, and LSD1 have poorer outcomes compared to those with lower expression of these genes. In SHH MB cell lines, REST elevation increased cell growth and LSD1 protein levels. Surprisingly, while genetic loss of LSD1 reduced cell viability, pharmacological targeting of its activity using LSD1 inhibitors did not affect cell viability. However, a reduction in REST-dependent cell migration was seen in wound healing, suggesting that REST-LSD1 interaction regulates cell migration. Ingenuity pathway analyses validated these findings and identified Hypoxia Inducible Factor 1 alpha (HIF1A) as a potential target. In line with this, ectopic expression of HIF1A rescued the loss of migration seen following LSD1 inhibition.

Conclusions: A subset of SHH patients display increased levels of LSD1 and REST, which is associated with poor outcomes. REST elevation in MB in conjunction with elevated LSD1 promotes MB cell migration. LSD1 inhibition blocks REST-dependent cell migration of MB cells in a HIF1A-dependent manner.

Keywords: LSD1, REST, SHH, Medulloblastoma, Tranylcypromine, HIF1A

\footnotetext{
* Correspondence: vgopalak@MDAnderson.org

'Department of Pediatrics, University of Texas M.D. Anderson Cancer Center,

Unit 853, 1515 Holcombe Blvd, Houston, TX 77030, USA

${ }^{2}$ Department of Molecular and Cellular Oncology, University of Texas M.D.

Anderson Cancer Center, Houston, TX 77030, USA

Full list of author information is available at the end of the article
}

(c) The Author(s). 2018 Open Access This article is distributed under the terms of the Creative Commons Attribution 4.0 International License (http://creativecommons.org/licenses/by/4.0/), which permits unrestricted use, distribution, and reproduction in any medium, provided you give appropriate credit to the original author(s) and the source, provide a link to the Creative Commons license, and indicate if changes were made. The Creative Commons Public Domain Dedication waiver (http://creativecommons.org/publicdomain/zero/1.0/) applies to the data made available in this article, unless otherwise stated. 


\section{Background}

Medulloblastoma (MB) is an embryonal tumor that arises in the hindbrain of pediatric patients. MB is currently classified into 4 molecular subgroups: Wingless (WNT), Sonic hedgehog (SHH), Group 3, and Group 4 [1]. These subgroups are further broken down into one or more of the following subtypes: alpha $(\alpha)$, beta $(ß)$, gamma $(\gamma)$, or delta $(\delta)$. Patients with WNT tumors have relatively good prognosis, permitting the investigation of de-escalated treatments for these patients in clinical trials [1-4]. However, a number of patients from the other MB subgroups, especially SHH and Group 3, exhibit metastasis and recurrence [1,3]. In fact, approximately $20 \%$ and $30 \%$ of all patients with $\mathrm{SHH}$ and Group 3 tumors, respectively, present with metastasis $[2,5]$. For these patients, the current standard of care is not curative and frequently results in unnecessary neurological toxicity. It is for these subsets of patients that the need for personalized and targeted therapy is dire.

Inhibitors targeting epigenetic modifiers such as histone deacetylases (HDAC), histone methyltransferases (HMT), and histone demethylases (HDM) are promising candidates in the hunt for targeted treatments. Perturbations in chromatin remodeling enzymes occur across all MB subgroups and are attractive therapeutic targets $[2,6]$. Several studies have demonstrated anti-tumorigenic activity with HDAC inhibitors in MB cells and upregulation of HDAC enzymes is established to dysregulate cell cycle [7, 8]. Work in our lab has focused on studying the feasibility of targeting the RE1-Silencing Transcription Factor (REST), a zinc finger DNA binding protein and transcription factor, which serves as a hub for the assembly of a number of chromatin remodelers including G9a, LSD1 and HDAC1/2 [9-11]. It recruits these enzymes through its amino-terminal mSIN3A or its carboxy-terminal coREST co-repressor complexes. REST is a repressor of neurogenesis and controls the expression of a number of genes involved in neuronal differentiation [12-15]. MBs are poorly differentiated tumors and previous work from a couple of groups including ours showed aberrant REST elevation in human MBs [16-19]. Both the expression and activity of REST and coREST has been implicated in poor patient prognosis and MB progression $[9,19,20]$. Our previous work showed the feasibility of targeting REST-coREST associated G9A activity as well as of targeting REST-mSIN3A associated HDAC1/2 in human MB cell lines $[19,21]$. Thus, while advances in targeting of the REST-coREST complex with HDAC and G9A inhibitors have been made, the role of another complex member, lysine specific demethylase 1 (LSD1), is poorly understood in $\mathrm{MB}[7,22,23]$. LSD1 demethylates lysine residues 4 and 9 on histone 3 tails (H3K4/H3K9) to canonically repress transcription, although it is also known to demethylate non-histone targets such as HIF1A [24-26]. Methylation of histone $\mathrm{H} 3 \mathrm{~K} 4 / \mathrm{H} 3 \mathrm{~K} 9$ is altered in $\mathrm{MB}$, and LSD1 levels are upregulated in both neuroblastoma and $\mathrm{MB}$ compared to normal tissue $[27,28]$. Although, LSD1 was described as a potential target in $\mathrm{MB}$ in 2013, its role in MB tumorigenesis has not been examined so far. In a previous study, it was demonstrated that LSD1 protein and transcript expression is increased in MB tumors over normal cerebellum, but the authors found no difference in expression between subgroups [27].

In this report, we discovered that $L S D 1$ gene expression is significantly elevated in the WNT, $\mathrm{SHH}$, and Group $3 \mathrm{MB}$ tumors compared to Group 4 MBs. This correlated with a trend for patients with metastasis to exhibit increased LSD1 expression. Interestingly, increased LSD1 gene expression was significantly associated with poor survival in patients with Group 3 tumors. To investigate if alterations in LSD1 activity rather than gene expression alone can be used for prognostication in $\mathrm{SHH}$ patients, we performed a clustering of $\mathrm{SHH}$ tumor samples using gene expression data of known LSD1 target genes in the brain along with target genes of its interacting partner-REST, the REST and LSD1-specific deubiquitylase (DUB) USP7, and genes known to contribute to MB metastasis. This approach identified clusters where higher LSD1 expression, especially in the context of higher-REST expression, correlated with poor patient outcomes compared to patients with lower expression of the above genes. In vitro experiments with human SHH MB cell lines revealed REST elevation to contribute to increased cell growth and migration. Cell growth could be blocked by genetic knockdown of LSD1. Surprisingly, pharmacological inhibition of LSD1 using a panel of irreversible inhibitors did not have an effect on cell growth. However, REST-dependent migration defects were reversed by irreversible LSD1 inhibition. Ingenuity Pathway Analysis (IPA) showed genes regulating cell migration to be differentially changed following LSD1 inhibition of MB cells. Amongst these genes, HIF1A, a molecule known to control glioma cell migration was most significantly downregulated by LSD1 inhibition [29, 30]. Constitutive HIF1A expression restored cell migration in LSD1 inhibitor-treated REST-high MB cells. HIF1A expression was significantly correlated with LSD1 and REST expression in SHH clusters with the metastatic $\alpha$ and $\beta$ subgroup of patients. Thus, our data suggest that study of LSD1 inhibitors in the context of SHH $\alpha$ and $\beta$ tumors warrants further exploration as a therapeutic option.

\section{Materials and methods}

\section{Analysis of patient data}

Patient data used for patient outcome and clustering analysis was sourced from previously published work done by Cavalli et al., 2017. The database is publicly available under accession number GSE85217. Z-scores 
for available genes were calculated and used as the basis for further examinations and correlations. Clinical data was paired with gene expression values. Two additional datasets are also publicly available on the $\mathrm{NIH}$ website under accession numbers GSE109401 and GSE37418.

\section{Statistics}

Spearman correlation between gene expression profiles was calculated using GraphPad Prism 5.0 (GraphPad Software Inc., San Diego, CA, USA). All $p$-values are two-sided with a $p<0.05$ considered to be significant. Hierarchical clustering was performed by ArrayTrack Software available at http://edkb.fda.gov/webstart/arraytrack/ using Ward's method. p-values for comparisons between clusters based on gene expression status were obtained using the unpaired t-test with Welch's correction.

\section{Cell culture}

UW228 and Daoy cells were obtained from American Type Cell Culture (ATCC). Cells were cultured and maintained in Dulbecco's modified eagle medium (DMEM) supplemented with $10 \%$ fetal bovine serum (FBS), $1 \times$ non-essential amino acids, and penicillin/streptavidin at $37^{\circ} \mathrm{C}$ in a $5 \% \mathrm{CO}_{2}$ incubator. Isogenic $\mathrm{MB}$ cell lines with endogenous and ectopically expressed REST (Daoy-REST; UW228-REST) were generated by viral transduction and selection for stable clones as described previously. Viral transduction of short hairpin RNA (shRNA) against LSD1 was done using Lipofectamine 2000 (Invitrogen). Cells were selected with puromycin and expanded for further experiments.

\section{MTT assay}

Tranylcypromine, GSKLSD1, and GSK2789552 are commercially available irreversible LSD1 inhibitors and were purchased from Sigma-Aldrich (Tranylcypromine and GSKLSD1) and Chemitek (GSK2789552). MTT assays were carried out according to standard protocol. Cells were seeded at a density of 3500 cells/well and incubated overnight. The following day, media was removed and fresh media with a range of drug doses were added to cells. At the end of 24, 48, and $72 \mathrm{~h}$ following drug addition, MTT reagent was added and spectrophotometer readings were taken at $595 \mathrm{~nm}$ and $650 \mathrm{~nm}$.

\section{Quantitative reverse transcriptase real-time polymerase chain reaction (qRT-PCR)}

RNA was isolated from cells using Qiagen RNA mini-prep kits. cDNA was prepared from isolated RNA using iSCRIPT and qRT-PCR reactions were performed following standard protocol in 96-well plates using a Roche LightCycler 96 machine. Cycle amplification data was processed with LightCycler software. Relative mRNA expression was calculated using the comparative
$\Delta \Delta$-Ct (cycle threshold) method and was normalized using $18 \mathrm{~S}$ expression.

Primers used are as follows:

REST forward: 5'-GTAGGAGCAGAAGAGGCAGAT-3' REST reverse: 5'-GCTTCACGTTCTTCTACTGCT-3' 18S forward: 5'-CGGCGACGACCCATTCGAAC-3' $18 S$ reverse: 5'-GAATCGAACCCTGATTCCCCGTC-3' BMP2 forward: 5'-AACACTGTGCGCAGCTTC-3' BMP2 reverse: 5'-TTCGGTGATGGAAACTGCTA-3' HIF1A forward: 5'-TGCTCATCAGTTGCCACTTC-3' HIF1A reverse: 5'-TCCTCACACGCAAATAGCTG-3'

\section{Boyden chamber assay}

24-well transwell Matrigel migration assay plates and control inserts were purchased from Corning (Catalog \#354480). Briefly, approximately $2.5 \times 10^{4}$ cells were seeded in $8 \mu \mathrm{M}$ pore-size transwell chambers. The bottom chamber was filled with $20 \%$ FBS to act as a chemoattractant. Cells were allowed to incubate for $22 \mathrm{~h}$ and were then fixed, stained with Hemistat triple pack and imaged under a microscope. Cell nuclei were counted from $4 \times$ images taken of the membrane insert. CellCounter software was used to automate the counting process. Cells were plated in triplicate and averaged.

\section{Scratch wound healing assay}

Cells were seeded onto 6-well plates in equal number and allowed to rest until confluent. A wound of equal width was made with a sterile $10 \mu \mathrm{L}$ pipette tip along the middle of the well. Media was aspirated and replaced with media containing $75 \mathrm{uM}$ GSKLSD1 or DMSO. Time points were taken every $6 \mathrm{~h}$ until the wound closed. Cells were transfected with a pcDNA3 plasmid expressing a constitutively active mutant HIF1A with P402A and P564A substitutions (Addgene) [31].

\section{RNA-Seq analyses}

Daoy cells were grown in $100 \mathrm{~cm}^{2}$ plates and treated with either $75 \mu \mathrm{M}$ of GSKLSD1 or DMSO. Cells were washed with phosphate buffered saline (PBS), pelleted, and snap frozen to be stored at $-80^{\circ} \mathrm{C}$. RNA Seq was performed at Active Motif (Carlsbad, CA) and data was processed into GeneDiff excel files. Data was examined by IPA for function assessment of gene expression changes.

\section{Results}

Analysis of patient samples based on LSD1 expression and activity

To investigate subgroup-specific differences in $L S D 1$ gene expression, we examined a publicly available dataset (GSE85217) of $763 \mathrm{MB}$ tumor samples. A significant analysis of variance (ANOVA) in LSD1 gene expression was observed ( $p<0.0001$; Fig. 1a) [3]. Within this dataset, 

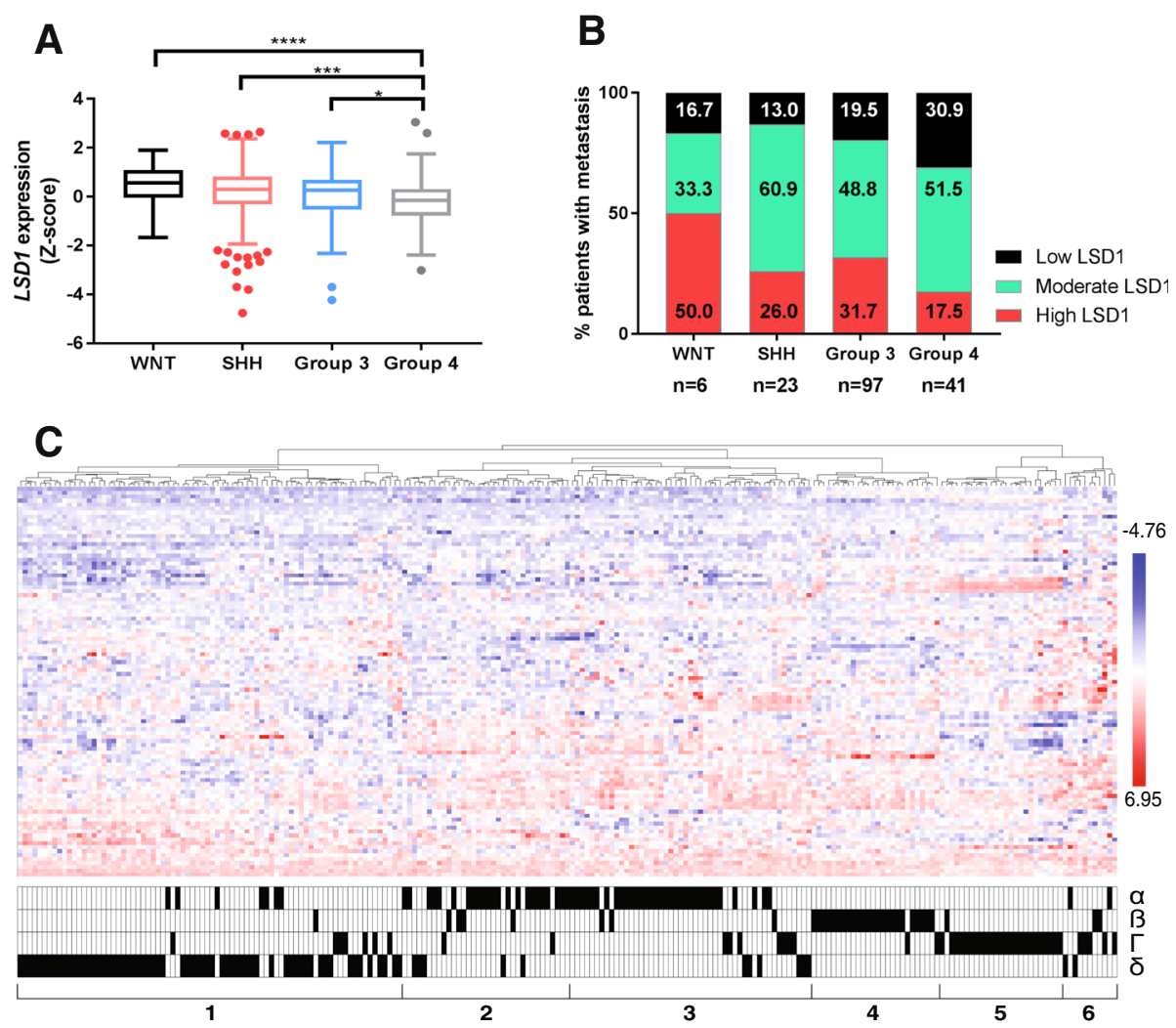

D

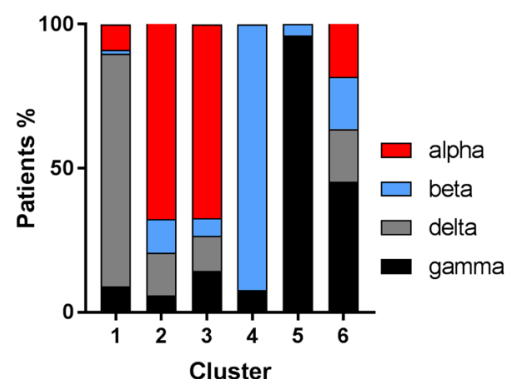

Fig. 1 Analysis of medulloblastoma patient samples by LSD1 expression and activity. Analysis of publicly available dataset containing 763 MB patient samples (GSE85217). a, Tukey box plots of Z-scores of LSD1 gene expression. The data points (circles) outside of the boxes represent outliers. ${ }^{*} p<0.01$; $\left.{ }^{* * *} p<0.003 ;{ }^{* * *} p<0.0001\right)$. b. Examination of patients with metastasis divided by LSD1 expression across subgroups. c, Clustering assay of SHH MB patient samples identified 6 distinct clusters based on predicted LSD1 activity. These clusters contained subtype-specific information (a, B, $\delta$, or $\Gamma$ ) provided in the bottom panel. d, Breakdown of SHH MB patient subtypes (alpha, beta, delta, gamma) per cluster (Cluster $1 n=78$; Cluster $2 n=34$; Cluster 3 n=49; Cluster 4 n=26; Cluster $5 n=25$; Cluster $6 n=11$ )

Group $4 \mathrm{MB}$ samples had significantly lower average LSD1 gene expression compared to WNT, SHH, or Group 3 tumors (Fig. 1a).

To better understand how LSD1 levels could affect patient outcomes, we divided patient samples based on the average Z-score of their LSD1 expression into three groups: low (Z-score $<-0.40)$, moderate $(-0.40<$ Z-score $<0.40)$, and high (Z-score $>0.40)$. Mantel-Cox analysis of survival only revealed a significant difference between low and moderate $L S D 1$ across all of the $\mathrm{MB}$ patients $(p<0.05$; Additional file 1A). A significant difference of survival was noted in patients with Group 3 but not the other MB subgroups (Additional file 1B-E). Although previous studies have shown that histone $\mathrm{H} 3 \mathrm{~K} 4$ methylation is perturbed in $\mathrm{SHH} \mathrm{MB}$, we did not see significant differences in survival based on LSD1 expression alone [28]. However, the SHH subgroup did have the most variable LSD1 expression range with 
outliers on both the low and high spectrum (Fig. 1a). Using the same classification, we observed that the majority of patients with metastasis across all MB subgroups had high or moderate levels of LSD1 (Fig. 1b). These results suggest that LSD1 gene expression alone may be predictive of metastasis but not survival in SHH MB patients.

Additional analysis of two other smaller MB datasets revealed a positive correlation of LSD1 and coREST-associated REST across SHH MB samples. However, these datasets did not include enough data or patient outcomes for further analysis (Additional file 1F, G; $r=0.48 p=0.08 ; r=0.92, p<0.05$ ).

To ask if $L S D 1$ co-elevation with other genes or perturbation of LSD1 activity in SHH tumors may have more predictive value, we performed clustering analysis using a cohort of 91 LSD1 target genes, the deubiquitylase USP7, and 8 REST and metastasis related genes in the brain [27, 32, 33] (Additional file 2A). This identified 6 clusters that aligned with subsets of the SHH subtypes (alpha $(\alpha)$, beta $(\beta)$, gamma $(\gamma)$, delta $(\delta)$ published previously by Cavalli et al. (Fig. 1c) (3). The composition of the clusters was as follows: Cluster $1-80 \%$ of $\mathrm{SHH} \delta$ tumors, Clusters 2 and 3 together added up of $78 \%$ SHH $\alpha$ tumors, Cluster 4-92\% SHH ß tumors, Cluster 5-96\% $\mathrm{SHH} \gamma$ tumors, and Cluster 6 was more undefined (Fig. 1d).

\section{Clustering of patient samples based on LSD1 activity is correlated with patient outcomes}

Using the associated gene expression microarray data, we examined the expression of REST, LSD1 and USP7 in the 6 clusters generated above (Additional file 2B). Interestingly, we found that the clusters containing the majority of the pediatric brain tumors (Clusters $2 / 3,4$, and $5 ; \alpha, \beta$, and $\Gamma$ respectively) had significant differences in the expression patterns of LSD1, REST, and USP7 (Additional file 2B). Focusing on these clusters, we compared Clusters 2-5 using bar plots. Cluster 2 (subset of SHH $\alpha$ tumors) was characterized by the highest increases in LSD1, REST, and USP7 expression, while Cluster 5 (SHH $\gamma$ tumors) exhibited the opposite pattern, with low expression of these genes (Fig. 2a). Clusters 3 (subset of SHH $\alpha$ tumors) and 4 (SHH ß) exhibited LSD1 and REST expression comparable to that in Cluster 2, but lacked significantly higher expression of USP7. In line with this, we also observed a strong correlation between LSD1 and REST (Fig. $2 \mathrm{~b} ; r=0.40, p<$ 0.0001 ) and LSD1 and USP7 (Fig. 2c; $r=0.38, \mathrm{p}<0.0001$ ). Of note, an overall significant positive correlation between LSD1 and REST and LSD1 and USP7 was also noted within all SHH MBs (Additional file 2C, D; $r=0.20, p=$ 0.002, $r=0.39 . \mathrm{p}<0.0001)$. Further, tumors in Clusters 1 and 6 had high LSD1 but not REST or USP7 expression levels (Additional file 2B). These results indicate that co-elevation of REST and LSD1 transcript or a simultaneous increase in their activity could occur in subsets of SHH tumors.

Examination of patient outcomes associated with these clusters revealed a significant difference in Mantel-Cox analysis of survival curves of Clusters 2-4 versus Cluster 5 (Fig. 2d; Additional file 2E; $p<0.05$ ). Analysis of metastasis occurrence within these clusters showed that Clusters $2 / 3$ and 4 contained a higher percentage of patients with metastasis than Cluster 5 (Fig. 2e). Together, these results suggest that subsets of patients within the SHH $\alpha$ and $\beta$ MB type have increased LSD1 and REST levels or activity and exhibit poor outcomes.

\section{$\angle S D 1$ is required for MB cell viability}

To understand the role of REST and LSD1 in MB cells, we first measured LSD1 and REST proteins levels in Daoy and UW228 SHH-MB cell lines. As expected, UW228 cells had lower REST and LSD1 when compared to DAOY cells (Fig. 3a). These cells were then engineered to ectopically express human REST transgene (Daoy-REST; UW228-REST) and cell extracts were evaluated by Western blotting for levels of REST and LSD1. We observed a significant increase in REST levels, which coincided with an increase in LSD1 protein levels (Fig. 3a). qPCR analysis of Daoy and UW228 cells also demonstrated a significant upregulation of REST transcript (3-fold and 2-fold) in high-REST cells (Fig. 3b). Surprisingly, LSD1 transcript showed a small but significant REST-associated elevation as well (1.5-fold and 1.3-fold), relative to their expression in parental cells (Fig. 3b).

To determine the relevance of LSD1 for growth of REST-expressing MB cells, LSD1 was knocked down in UW228, DAOY and Daoy-REST cells and its effect on cell numbers was determined. Efficiency of LSD1 knock down was confirmed by qRT-PCR and Western blot analyses (Figs. 3c, d). Interestingly, LSD1 loss promoted a reduction in REST protein levels in all three cell lines (Fig. 3d). LSD1 loss in Daoy and UW228 cells in response to $L S D 1$-specific shRNA (shLSD1) expression caused a significant reduction in their growth as measured by MTT assays when compared to cells transduced with control (Ctrl) shRNAs (Fig. 3e; Additional file 3A-C). A reduction in the number of $\mathrm{MB}$ cells was also noted in light microscopy images following LSD1 knockdown when compared to control shRNA transduced cells (Fig. 3e and f, right panels; Additional file 3A-C). As expected, REST elevation caused an early increase in cell growth of Daoy cells, but this cell growth advantage was reduced by genetic knockdown of LSD1 (Fig. 3f; Additional file 3A-C). These results indicate that LSD1 is required for REST-dependent growth of MB cells. LSD1 knockdown also promoted Caspase-3 cleavage, indicating induction of apoptosis (Fig. 3d). 

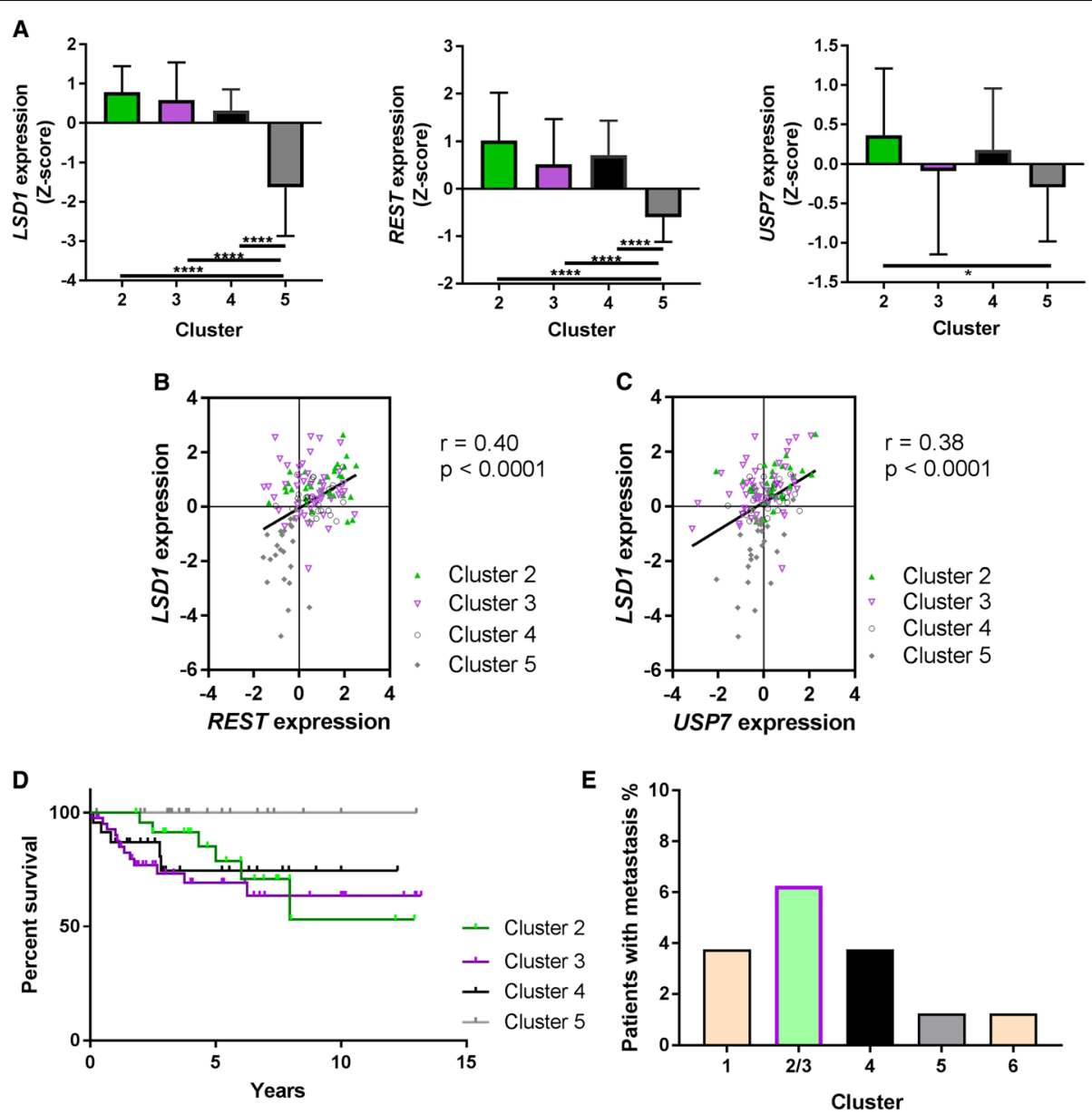

Fig. $2 \mathrm{MB}$ patient samples clustered based on LSD1 activity are related to patient outcomes. a, Bar graphs of expression of LSD1, REST, and USP7 in Clusters 2, 3, 4, and $5\left(^{*} p<0.05 ;{ }^{* * *} p<0.0001\right)$. Combined expression of USP7 with Cluster 2, 3, and 4 was significantly higher than Cluster 5 $(p<0.05)$. b, Scatter plot of correlation of REST and LSD1 across Clusters $2-5(r=0.40, p<0.0001)$. c, Scatter plot of correlation of LSD1 and USP7 across Clusters $2-5(r=0.38, p<0.0001)$. d, Patient survival (Kaplan-Meier curves) associated with Clusters 2, 3, 4, and 5 . Clusters 2 vs. Cluster 5 had a significant Mantel-Cox test $(p<0.05)$. Cluster 3 vs. Cluster 5 had a significant Mantel-Cox $(p<0.01)$ and Gehan-Breslow-Wilcoxon test $(p<0.05)$. Cluster 4 vs. Cluster 5 had a significant Mantel-Cox $(p<0.01)$ and Gehan-Breslow-Wilcoxon test $(p<0.05)$. Combined Clusters 2 and 3 vs. Cluster 5 had a significant Mantel-Cox $(p<0.05)$ and Gehan-Breslow-Wilcoxon test $(p<0.05)$. ctrl: control. e, Percentage of metastasis within each cluster

\section{Pharmacological inhibition of LSD1 counters REST- dependent MB cell migration}

To validate the above findings, we also examined the effect of pharmacological inhibition of LSD1 activity on MB cell viability. A panel of irreversible LSD1 inhibitors (Tranylcypromine, GSKLSD1 and GSK2789552) was evaluated with MTT assays using isogenic pairs of UW228/UW228-REST and Daoy/Daoy-REST cells [34]. To our surprise, we observed that none of the irreversible inhibitors had any effect on the growth or number of SHH MB cell lines UW228 and Daoy cells up to a $100 \mu \mathrm{M}$ dose (Additional file 4A). REST elevation did not influence the effect of these agents on UW228-REST or Daoy-REST cells (Additional file 4B).

However, we observed a REST-dependent increase in migration of $\mathrm{MB}$ cells in vitro. Daoy cells with higher REST expression could more rapidly narrow the wound in scratch assays (18 h) compared to UW228 cells, which required $24 \mathrm{~h}$ for a similar effect (Fig. 4a, B). This effect of REST elevation on cell migration was further corroborated by similar studies comparing migration of isogenic Daoy and Daoy-REST as well as UW228 and UW228-REST cell pairs (Fig. 4a, b). Interestingly, Daoy-REST cells displayed resistance to LSD1 inhibition at the lower dose $(5 \mu \mathrm{M})$, requiring a dose of $75 \mu \mathrm{M}$ to significantly reduce migration (Fig. 4b). These results were confirmed by Boyden chamber assays to determine transwell migration of Daoy and Daoy-REST cells to fetal bovine serum (FBS). GSKLSD1 treatment at $75 \mu \mathrm{M}$ was sufficient to significantly reduce cell migration over time in both Daoy and Daoy-REST cells (Fig. 4c). Together our results suggest that irreversible LSD1 inhibition blocks REST-dependent MB cell migration. 

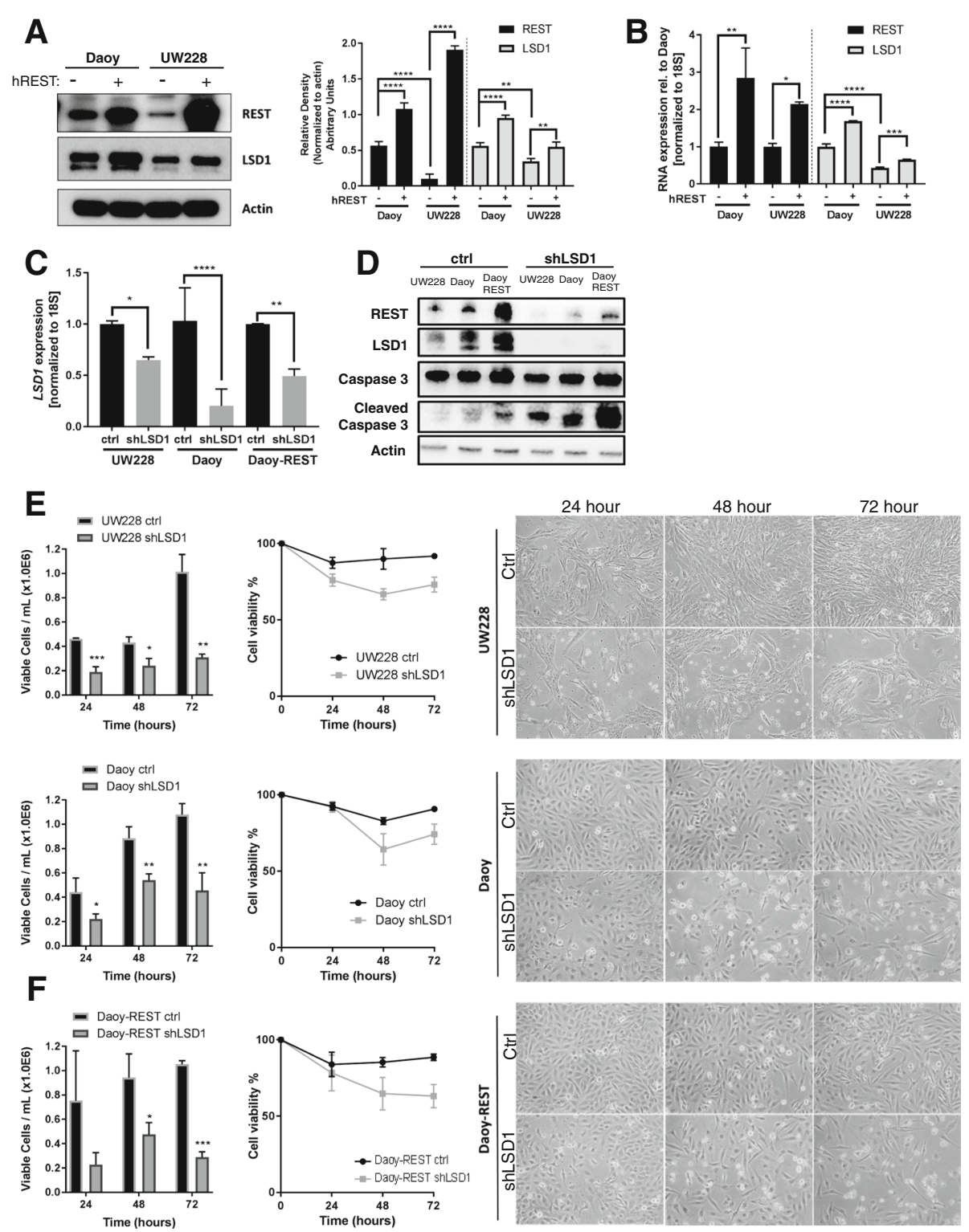

Fig. 3 LSD1 expression is increased by elevated REST and cell growth is blocked by LSD1 knockdown in SHH MB cell lines. a, Western blot of REST and LSD1 protein levels in cell pairs (UW228, Daoy) with and without the human REST transgene (hREST; UW228-REST, Daoy-REST) (left panel). Quantification of REST (black) and LSD1 (grey) protein density normalized to actin loading control (right panel; ${ }^{* *} p<0.01,{ }^{* * *} p<0.000$ ). b, qPCR analysis of REST (black) and LSD1 (grey) expression normalized to $185\left({ }^{*} p<0.05,{ }^{* *} p<0.01,{ }^{* * *} p<0.001,{ }^{* * * *} p<0.0001\right)$. c, qPCR analysis of LSD1 expression in UW228, Daoy, and Daoy-REST cells treated with shLSD1 ( $\left.{ }^{*} p<0.05,{ }^{* *} p<0.01,{ }^{* * *} p<0.0001\right)$. d, Western blot of REST, LSD1, Caspase 3, Cleaved Caspase 3, and actin protein levels in control (ctrl) and shLSD1 treated cells. e, Cell viability as measured by trypan blue counting in UW228, Daoy, and $\mathbf{f}$, Daoy-REST cells. Graphs represented as viable cell count $/ \mathrm{mL}$ and \% cell viability. Pictures represent cell confluency at 24,48 , and $72 \mathrm{~h}$ post-transduction $\left({ }^{*} p<0.05 ;{ }^{* *} p<0.01 ; * * p<0.001\right)$

\section{Irreversible inhibition of LSD1 alters cellular migration machinery}

To study the molecular changes in MB cells in response to drug treatment, we performed RNA-Seq analyses of Daoy cells treated with $75 \mu \mathrm{M}$ of GSKLSD1. IPA was performed to identify changes in the transcriptome. Volcano plot represents a total of 451 genes that were significantly altered in response to drug treatment
(Fig. 5a). Of these, 200 genes were upregulated and 251 were downregulated by GSKLSD1 treatment $(p<0.05$; Fig. 5a). Functional analysis identified several altered functions relevant to cancer (Fig. 5b). Gene expression changes controlling cell survival/death, cell-cell interaction and cellular movement were a few of the most highly altered molecules (Fig. 5b). Since LSD1 and REST elevation was associated with a higher incidence of 

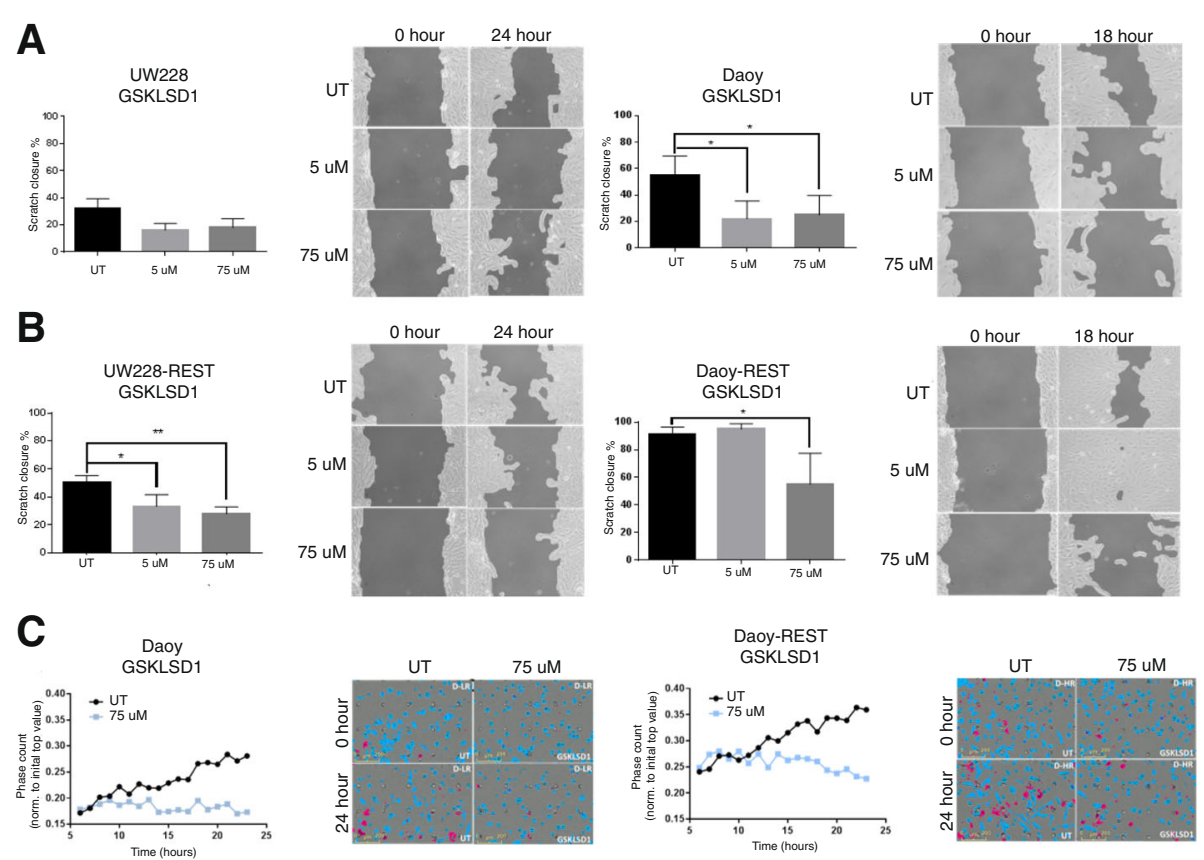

Fig. 4 Pharmacological inhibition of LSD1 reduces cell migration of SHH MB cell lines. a, Scratch wound migration assay of UW228 and Daoy cells at low dose $(5 \mathrm{uM})$ and high dose $(75 \mathrm{uM})$ of GSKLSD1. b, Scratch wound migration assay of UW228-REST and Daoy-REST cells at low dose ( 5 uM) and high dose $\left(75\right.$ UM) of GSKLSD1 $\left({ }^{*} p<0.05,{ }^{* *} p<0.01\right)$. UW228-REST and Daoy-REST cells migrate twice as fast as UW228 and Daoy cells, respectively $(p<0.05)$. $\mathbf{c}$, Transwell migration of Daoy and Daoy-REST cells over $24 \mathrm{~h}$ at $75 \mathrm{uM}$ of GSKLSD1. Slope of migration is significantly reduced $(p<0.05)$

metastasis in patients (Fig. 1), we carried out a more detailed examination of the "cellular adhesion and movement" category, which identified a number of significantly altered genes related to tumor cell migration (Fig. 5c). Interestingly, one of the most significantly reduced genes in this subset was hypoxia inducible factor 1 alpha (HIF1A).

Work from other groups has implicated REST and LSD1 in the control of HIF1A expression and activity [26, 35-37]. Consistent with these findings, GSKLSD1 significantly downregulated HIF1A levels in Daoy and UW228 cells (Fig. 5d; $p<0.01$ and $p<0.0001$ ). Further, REST elevation countered reduction in HIF1A in Daoy-REST cells, but not in UW228-REST cells (Fig. 5e; $p<0.0001$ and $p>0.05$ ).

To verify the role of HIF1A in GSKLSD1-associated migration blockade, $\mathrm{MB}$ cell lines were transfected with a plasmid expressing a constitutively active mutant of $H I F 1 A$, treated with the GSKLSD1 $(75 \mu \mathrm{M})$, and effect on cell migration was examined by scratch wound assay. A significant rescue of wound closure was observed in Daoy-REST and UW228-REST cells, but not Daoy and UW228 cells, treated with GSKLSD1 and HIF1A (Fig. 5f, $p<0.01)$. These results implicate HIF1A in promoting LSD1-dependent cell migration in REST-high MB cells.

Analysis of MB patient samples revealed a significant elevation of HIFA in Clusters 2 and 4 compared to
Cluster 5 (Fig. $5 \mathrm{~g}$ ). A positive correlation between REST and HIF1A expression was also seen across the clusters that were predominantly comprised of pediatric $\mathrm{MB}$ tumors, and across all SHH MBs (Fig. 5h; $r=0.38$; $\mathrm{p}<$ 0.0001; Additional file 5A, B). Further, HIF1A expression was highest in tumors with the largest increases in REST expression (Fig. 5i; Clusters 2 and 4). LSD1 and HIF1A expression were are also positively correlated in these samples (Fig. 5i; $r=0.26 ; p<0.01$ ). These correlations were also recapitulated in two smaller patient cohorts (Additional file 5A-D). Together, our results indicate that REST-associated LSD1-activity regulates HIF1A expression and that HIF1A may contribute to REST-LSD1 dependent $\mathrm{MB}$ cell migration.

\section{Discussion}

LSD1, also called KDM1A/AOF2/BHC110, is a key component of several transcriptional repressor complexes, where it mediates demethylation of histone H3K4 mono and dimethyl marks, and turns off gene expression [3840]. It is also known to activate transcription by demethylation of the repressive histone H3K9 mono and dimethyl marks [41]. Of importance to this study is the association of LSD1 with the REST-coREST complex, which controls neuronal lineage specification in neural cells [12, 42, 43]. LSD1 upregulation has been described in $\mathrm{MB}$ tumors by a previous study which examined its 


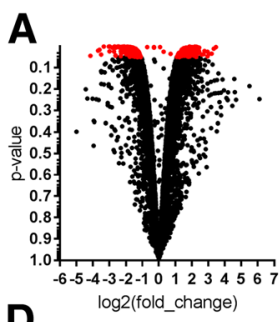

D
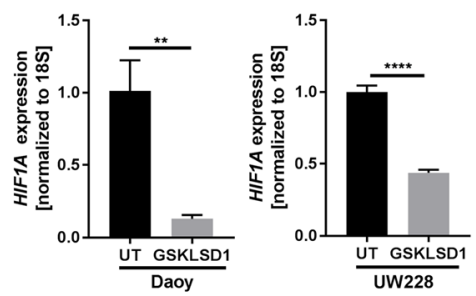

$\mathbf{F}$

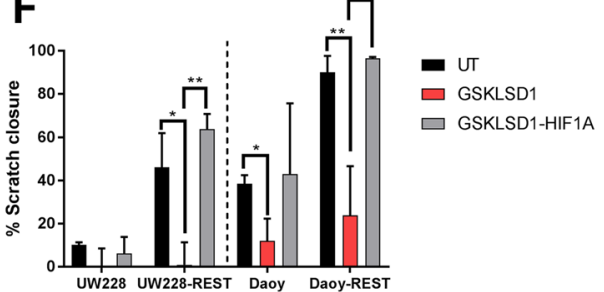

H

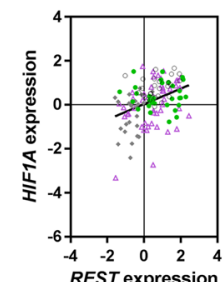

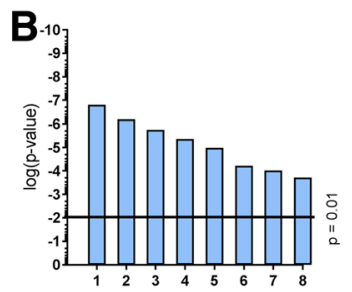

E
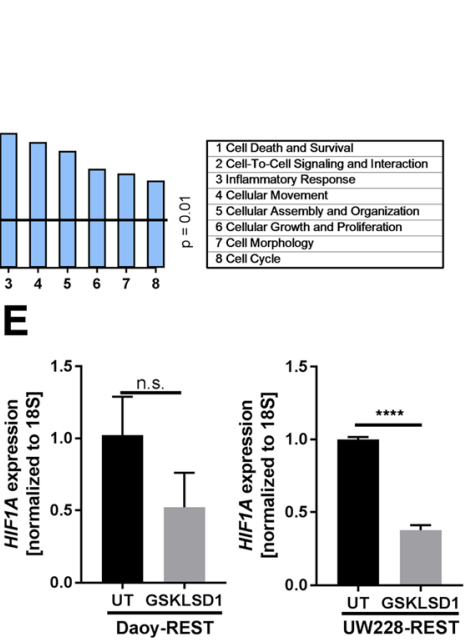

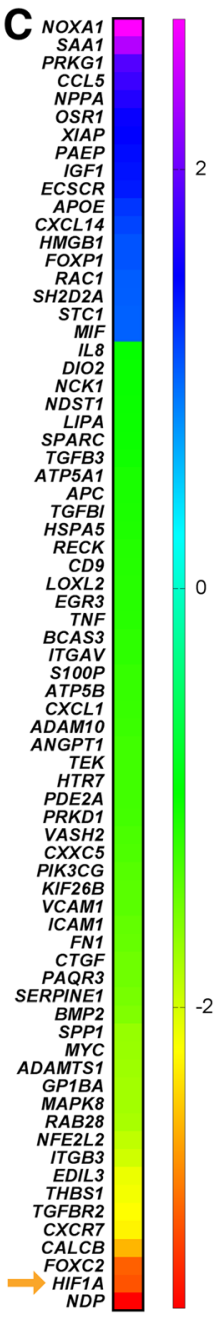

Fig. 5 Pharmacological inhibition of LSD1 alters expression of MB and migration related genes. $\mathbf{a}$, Volcano plot of expression changes from RNAsequencing data. 451 altered genes with $p<0.05$. b. Ingenuity pathway analysis of function revealed top functions outside of cancer. $\mathbf{c}$, Heat map of log2fold gene expression changes in the cell adhesion and migration function. Orange arrow highlights HIF1A. d, qPCR analysis of HIF1A expression in Daoy and UW228 cells treated with GSKLSD1 $\left(^{* *} p<0.01 ;{ }^{* * *} p<0.0001\right)$. e, qPCR analysis of HIF1A expression in Daoy-REST and UW228-REST cells treated with GSKLSD1 $\left(p=0.07 ;{ }^{* * * *} p<0.0001\right)$. f, Scratch wound migration assay of UW228, UW228-REST, Daoy, and Daoy-REST cells in three conditions: untreated (UT), GSKLSD1 (75 uM), or GSKLSD1-HIF1A (75 uM) ( ${ }^{*} p<0.05,{ }^{* *} p<0.01$, $\left.{ }^{* *} p<0.001\right)$. g, Bar plot of HIF1A expression in Clusters 2, 3, 4, and $5\left({ }^{* * *} p<0.001 ;{ }^{* * * *} p<0.0001\right)$. h, Scatter plot of correlation of REST and HIF1A across Clusters 2, 3, 4, and 5 $(r=0.36, p<0.001)$. I, Scatter plot of correlation of LSD1 and HIF1A across Clusters 2,3 , 4, and $5(r=0.27, p<0.01)$

gene and protein expression across the different $\mathrm{MB}$ groups in a cohort of 93 patient samples [27]. However, this study did not find a significant difference in $L S D 1$ gene expression between the MB groups, although a separate study by Dubuc et al., demonstrated significant perturbations in histone H3K4 methylation, especially across Group 3 and Group $4 \mathrm{MB}$ samples [28, 44]. In this study, we analyzed a larger, publicly available patient dataset of $763 \mathrm{MB}$ samples, and found by contrast a significant increase in LSD1 expression in SHH, Group 3, and Group 4 compared to WNT MB samples. Importantly, LSD1 expression appeared to be elevated in a majority of patients with $\mathrm{SHH}$, Group 3, and Group 4 tumors who exhibited metastasis, suggesting that targeting LSD1 may have relevance to patients with metastatic disease.

In the current report, we quantified LSD1 activity across patient samples from the SHH MB subgroup, where survival did not seem to correlate with changes in LSD1 transcript expression alone. LSD1 activity and or stability is known to be regulated at the post-transcriptional level either by its phosphorylation, hydroxylation or its association with transcription factors such as REST [9, 24, 25, 43]. To examine SHH MB samples based on LSD1 function specifically in the context of REST transcriptional activity, we clustered samples based on expression of known LSD1 
targets along with known REST-target genes and USP7, a gene that encodes a deubiquitylase controlling REST and LSD1 protein stability. Thus, six distinct clusters were generated, which helped identify co-elevation of REST, LSD1 and USP7 in a subset SHH $\alpha$ tumors (Cluster 2), thus potentially correlating REST-LSD1 protein stability to metastasis $[45,46]$. While Cluster 3 (the second subset of SHH $\alpha$ tumors) also had elevated REST and LSD1 gene expression, USP7 expression was not as elevated and consistent with this, LSD1 activity was not as elevated. SHH $\alpha$ tumors are also characterized by $M Y C N$ expression and $\mathrm{p} 53$ mutations in non-infant children with a median age of 8 years [3]. Although, this has not been evaluated in this study, it is possible that LSD1 (and REST) dysregulation could contribute to the poor prognosis in this cluster of patients by affecting p53 and MYCN function in the tumor [47]. Cluster 4 (SHH $ß$ subtype) tumors, which occur predominantly in infants, was also associated with increased LSD1 and USP7 expression, but had a more modest increase in REST gene expression. Thus, the poor prognosis seen with this cohort of patients may be either less-REST dependent, or more dependent on REST protein levels, which is controlled by $\beta$-TRCP complex of ubiquitin ligases, and DUBs such as USP15 and USP7 [48]. Clearly, Cluster 5 tumors with a pattern of low REST, LSD1 and USP7 gene expression included patients with $\mathrm{SHH} \gamma$ patients, who are known to have good prognosis [3]. Finally, Cluster 1 included samples from patients with SHH $\delta$ subtypes of MBs. Here, a dramatic reduction in overall survival correlated with elevated $L S D 1$ expression in the absence of upregulation of REST expression. This is interesting, as SHH $\delta$ patients are largely adults with a median age of 26 years [3]. Adult MB is rare and treatment protocols are identical to that used for pediatric patients, despite differences in underlying tumor biology $[49,50]$. Many of these patients present with telomerase reverse transcriptase (TERT) promoter mutations or methylation, increasing the expression of TERT to contribute to oncogenesis [51-53]. Interestingly, REST and LSD1 have both been implicated in repressing TERT gene expression by promoting repressive epigenetic marks to promote chromatin condensation [54, 55]. Whether, LSD1 elevation, dependent or independent of REST activity, affects TERT expression remains to be evaluated in laboratory studies. Thus, this analysis is the first to identified subsets of patients who may have increased activity of REST-LSD1 complex or LSD1 activity in the context of other transcription factors, and who may benefit from treatment with LSD1 inhibitors [3, 27].

Consistent with our findings from analyses of patient data, our in vitro experiments confirmed that elevation of REST expression increased $\mathrm{MB}$ cell growth and migration. This elevation in REST occurred concomitant with increased LSD1 expression at both the transcript and protein levels. Changes in protein levels can be partly explained by the fact that the stability of both REST and LSD1 stability is controlled by USP7 [45]. However, other components of the REST-coREST complex such as G9a are also increased in a REST-dependent manner. A potential explanation may be that increases in REST protein levels may cause sequestration of other complex components. Indeed, the LSD1-RCOR1 interaction protects LSD1 from proteasomal degradation [34, 38]. The decrease in REST levels associated with LSD1 loss in our studies suggests that the reverse may also be true. However, the increase in LSD1 levels was higher in Daoy-REST cells than in UW228-REST cells, although higher levels of exogenously expressed REST could be maintained in UW228-REST cells. Thus, there probably exists additional explanations for how stoichiometry of the REST complex is preserved to allow greater activity. The reason for co-elevation of REST and LSD1 transcript is not clear at this time.

The observation that LSD1 knockdown but not pharmacological inhibition of LSD1 suppressed growth of SHH MB is intriguing. LSD1 is known to act as a scaffold to allow maintenance of coREST complex integrity [43]. Thus, it is conceivable that loss of LSD1 could destabilize the REST-coREST complex, which is supported by the observation that REST levels decline upon LSD1 knockdown. Since REST is required for MB cell viability, loss of LSD1 and REST would be expected to affect cell survival. GSKLSD1 is an irreversible LSD1 inhibitor derived from tranylcypromine and made more specific to LSD1 by the addition of a N-amine substituent [56-58]. This class of inhibitors blocks LSD1 demethylase activity by blocking FAD-dependent cleavage of mono- and di- methyl residues. However, LSD1 inhibition may not necessarily affect REST-coREST stability. In that case, LSD1 may retain its scaffolding function and REST activity may only be partially inhibited. This possibility remains to be investigated in future studies.

Although pharmacological inhibition of LSD1 with irreversible inhibition did not affect cell growth, cell migration was affected by GSKLSD1. Further, we found that REST-dependent HIF1A upregulation was reduced by irreversible LSD1 inhibition, suggesting that the REST-LSD1 complex may control HIF1A gene expression and/or function. Whether post-transcriptional mechanisms of regulation of HIF1A also occurs in our system, remains to be investigated. The contribution of HIF1A to the control of cell migration has been reported in a number of tumors including gliomas, and our findings are consistent with these observations [29, 30]. We observed that ectopic expression of constitutively active HIF1A rescued the loss of cell migration seen following GSKLSD1 treatment of REST-high MB cells. Together, our results suggest a subtype-specific relevance for LSD1 
inhibitors as a therapeutic option and identify HIF1A as a novel downstream target of irreversible LSD1 inhibition in the context of REST elevation.

\section{Conclusions}

Our work demonstrates that examination of LSD1 transcript expression is an insufficient measure to assess the contribution of $L S D 1$ to MB tumors. Further, we show that LSD1 activity may be perturbed in the context of REST protein dysregulation in SHH $\alpha$ and $\beta$ tumors. Surprisingly, a strong correlation between $L S D 1$ elevation and poor survival was noted in patients with $\mathrm{SHH}-\delta$ tumors, which exhibit deregulated TERT expression. These results suggest that specific subsets of patients with $\mathrm{SHH}$ tumors may benefit from treatment with LSD1 inhibitors. Our in vitro assays and IPA data appear to support a role for LSD1 in metastatic MBs and identify HIF1A as a novel potential target of LSD1 inhibition in the context of REST. However, additional studies are needed to fully understand the extent of LSD1 regulation of MB tumor biology.

\section{Additional files}

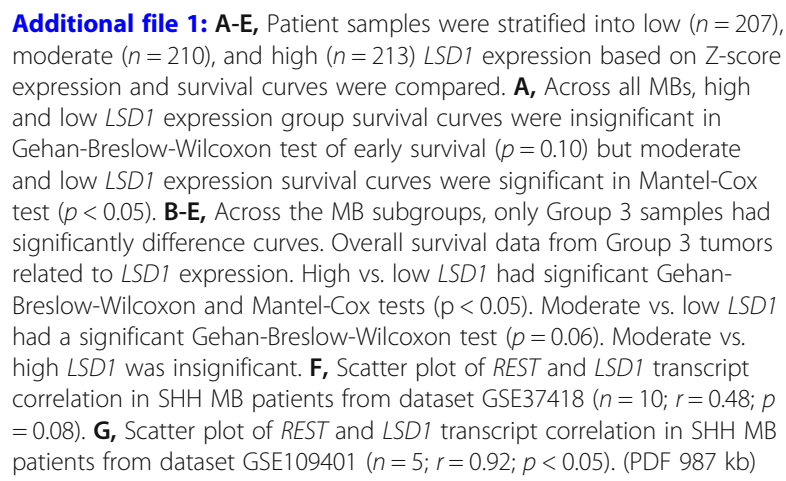
moderate $(n=210)$, and high $(n=213)$ LSD1 expression based on Z-score expression and survival curves were compared. A, Across all MBs, high and low LSD1 expression group survival curves were insignificant in Gehan-Breslow-Wilcoxon test of early survival $(p=0.10)$ but moderate and low LSD1 expression survival curves were significant in Mantel-Cox test $(p<0.05)$. B-E, Across the MB subgroups, only Group 3 samples had significantly difference curves. Overall survival data from Group 3 tumors related to $L S D 1$ expression. High vs. Iow $L S D 1$ had significant GehanBreslow-Wilcoxon and Mantel-Cox tests $(p<0.05)$. Moderate vs. Iow LSD1 had a significant Gehan-Breslow-Wilcoxon test $(p=0.06)$. Moderate vs. high LSD1 was insignificant. F, Scatter plot of REST and LSD1 transcript correlation in SHH MB patients from dataset GSE37418 $(n=10 ; r=0.48 ; p$ $=0.08)$. G, Scatter plot of REST and $L S D 1$ transcript correlation in SHH MB patients from dataset GSE109401 ( $n=5 ; r=0.92 ; p<0.05$ ). (PDF $987 \mathrm{~kb})$

Additional file 2: A, Listed genes used for clustering analysis in the order of top-down pictured in Fig. 1C. B, Box plots of LSD1, REST, and USP7 expression $\left({ }^{*} p<0.05 ;{ }^{* *} p<0.01 ;{ }^{* * *} p<0.001 ;{ }^{* * * *} p<0.0001\right)$. C, Scatter plots of REST and LSD1 correlation across the whole SHH MB cohort and across each Cluster 1-6 (Cluster $1 n=78$; Cluster $2 n=34$; Cluster 3 $n=49$; Cluster $4 n=26$; Cluster $5 n=25$; Cluster $6 n=11$ ). D, Scatter plots of USP7 and LSD1 correlation across the whole cohort and across each Cluster 1-6. E, Kaplan-Meier survival curve of all Clusters 1-6. (PDF 1450 $\mathrm{kb})$

Additional file 3: Light microscopy images of Daoy, UW228, and DaoyREST cells treated with control and shLSD1 at A, 24 h, B, 48 h, and C, $72 \mathrm{~h}$. Experiments were completed in triplicate. (PDF $14333 \mathrm{~kb}$ )

Additional file 4: A, MTT assay of $24 \mathrm{~h}$ and $48 \mathrm{~h}$ time points with three different LSD1 inhibitors (Tranylcypromine, GSKLSD1, and GSK2789552) in Daoy and UW228 cells showing no dose-response in response to up to $100 \mathrm{uM}$ drug dosage. B, MTT assay of $24 \mathrm{~h}$ and $48 \mathrm{~h}$ timepoints with three different LSD1 inhibitors (Tranylcypromine, GSKLSD1, and GSK2789552) in isogenic high-REST counterparts, Daoy-REST and UW228REST cells, showing no dose-response in response to up to $100 \mathrm{uM}$ drug dosage. (PDF $1067 \mathrm{~kb}$ )

Additional file 5: A, Scatter plots of REST and HIFIA correlation across the whole SHH MB cohort and across each Cluster 1-6. Clusters 3 and 4 had majority of points located in the top right quadrant of the graph, indicating high expression of these transcripts, while Cluster 5 had lower left localization indicating lower expression levels. B, Scatter plots of REST and HIFIA transcript correlation in SHH MB patients from dataset GSE37418 $(n=10 ; r=0.59 ; p<0.05)$. G, Scatter plot of REST and HIF1A transcript correlation in SHH MB patients from dataset GSE109401 $(n=5$; $r=0.42 ; p=0.23$ ). . C, Scatter plots of $L S D 1$ and HIF1A correlation across the whole SHH MB cohort and across each Cluster 1-6. Clusters 2-4 had majority of points located in the top right quadrant of the graph, indicating high expression of these transcripts, while Cluster 5 had lower left localization indicating lower expression levels. D, Scatter plots of LSD1 and HIF1A transcript correlation in SHH MB patients from dataset GSE37418 $(n=10 ; r=0.22 ; p=0.27)$. G, Scatter plot of REST and HIFIA transcript correlation in SHH MB patients from dataset GSE109401 $(n=5$; $r=0.67 ; p=0.11$ ). (Cluster $1 n=78$; Cluster $2 n=34$; Cluster $3 n=49$; Cluster $4 n=26$; Cluster $5 n=25$; Cluster $6 n=11$ ). (PDF $1382 \mathrm{~kb}$ )

\section{Abbreviations}

BMP2: Bone Morphogenic Protein 2; CoREST: Corepressor REST;

HIF1A: Hypoxia Inducible Factor 1 alpha; LSD1: Lysine Specific Demethylase 1; MB: Medulloblastoma; REST: RE1 Silencing Transcription Factor; SHH: Sonic Hedghog; USP7: ubiquitin specific protease 7; WNT: Wingless

\section{Acknowledgements}

Much appreciation is given to Dr. Joya Chandra and Cavan Bailey for generously supplying the shLSD1 plasmid used in this work.

\section{Funding}

Research reported in this publication was supported by the National Center for Advancing Translational Sciences of the National Institutes of Health (NIH) under Award Numbers TL1TR000369 and UL1TR000371 to KC and Award Number R01NS079715 to VG, Cancer Prevention Research Institute of Texas (CPRIT) grant RP150301 and Rally Foundation for Childhood Cancers to VG. The content is solely the responsibility of the authors and does not necessarily represent the official views of the $\mathrm{NIH}$ and CPRIT.

\section{Availability of data and materials}

The datasets used and/or analyzed during the current study are available in the National Center for Biotechnology Information (NCBI) repository, https:// www.ncbi.nlm.nih.gov/geo/query/acc.cgi?acc=GSE85217 or are available from the corresponding author on reasonable request. Accession numbers: GSE85217. GSE109401, GSE37418.

\section{Authors' contributions}

KC: contributions to conception, experimental design and execution of all in vitro work, GPCR experiments, and patient data analysis, figure composition, writing, and editing. SM: contributions to experimental design and execution of clustering analysis of patient data, writing methods, and editing. JBA: contributions to experimental execution and design of GPCR work and editing. VG: contributions to conception, design, writing and editing. All authors have read and approved the final manuscript.

\section{Ethics approval and consent to participate}

N/A

\section{Consent for publication}

N/A

\section{Competing interests}

The authors declare that they have no competing interests.

\section{Publisher's Note}

Springer Nature remains neutral with regard to jurisdictional claims in published maps and institutional affiliations.

\section{Author details}

'Department of Pediatrics, University of Texas M.D. Anderson Cancer Center, Unit 853, 1515 Holcombe Blvd, Houston, TX 77030, USA. ${ }^{2}$ Department of Molecular and Cellular Oncology, University of Texas M.D. Anderson Cancer Center, Houston, TX 77030, USA. ${ }^{3}$ Department of Center for Cancer Epigenetics, University of Texas M.D. Anderson Cancer Center, Houston, TX 77030, USA. ${ }^{4}$ Department of Brain Tumor Center, University of Texas M.D. 
Anderson Cancer Center, Houston, TX 77030, USA. ${ }^{5}$ The University of Texas MD Anderson Cancer Center UTHealth Graduate School of Biomedical Sciences, Austin, USA.

Received: 29 May 2018 Accepted: 13 September 2018 Published online: 18 September 2018

\section{References}

1. Taylor MD, Northcott PA, Korshunov A, Remke M, Cho YJ, Clifford SC, Eberhart CG, Parsons DW, Rutkowski S, Gajjar A, et al. Molecular subgroups of medulloblastoma: the current consensus. Acta Neuropathol. 2012;123: 465-72.

2. Northcott PA, Korshunov A, Pfister SM, Taylor MD. The clinical implications of medulloblastoma subgroups. Nat Rev Neurol. 2012;8:340-51.

3. Cavalli FMG, Remke M, Rampasek L, Peacock J, Shih DJH, Luu B, Garzia L, Torchia J, Nor C, Morrissy AS, et al. Intertumoral heterogeneity within Medulloblastoma subgroups. Cancer Cell. 2017;31:737-54 e736.

4. A Clinical and Molecular Risk-Directed Therapy for Newly Diagnosed Medulloblastoma. https://ClinicalTrials.gov/show/NCT01878617. Web. 14 September 2018

5. Kool M, Korshunov A, Remke M, Jones DT, Schlanstein M, Northcott PA, Cho YJ, Koster J, Schouten-van Meeteren A, van Vuurden D, et al. Molecular subgroups of medulloblastoma: an international meta-analysis of transcriptome, genetic aberrations, and clinical data of WNT, SHH, group 3, and group 4 medulloblastomas. Acta Neuropathol. 2012;123:473-84.

6. Roussel MF, Stripay JL. Epigenetic drivers in pediatric Medulloblastoma. Cerebellum. 2018;17:28-36.

7. Milde T, Oehme I, Korshunov A, Kopp-Schneider A, Remke M, Northcott P, Deubzer HE, Lodrini M, Taylor MD, von Deimling A, et al. HDAC5 and HDAC9 in medulloblastoma: novel markers for risk stratification and role in tumor cell growth. Clin Cancer Res. 2010;16:3240-52.

8. Ma JX, Li H, Chen XM, Yang XH, Wang Q, Wu ML, Kong QY, Li ZX, Liu J. Expression patterns and potential roles of SIRT1 in human medulloblastoma cells in vivo and in vitro. Neuropathology. 2013;33:7-16.

9. Inui K, Zhao Z, Yuan J, Jayaprakash S, Le LTM, Drakulic S, Sander B, Golas MM. Stepwise assembly of functional C-terminal REST/NRSF transcriptional repressor complexes as a drug target. Protein Sci. 2017;26:997-1011.

10. Qureshi IA, Gokhan S, Mehler MF. REST and COREST are transcriptional and epigenetic regulators of seminal neural fate decisions. Cell Cycle. 2010;9:4477-86

11. Kalin JH, Wu M, Gomez AV, Song Y, Das J, Hayward D, Adejola N, Wu M, Panova I, Chung HJ, et al. Targeting the CoREST complex with dual histone deacetylase and demethylase inhibitors. Nat Commun. 2018;9:53.

12. Abrajano JJ, Qureshi IA, Gokhan S, Zheng D, Bergman A, Mehler MF. REST and COREST modulate neuronal subtype specification, maturation and maintenance. PLoS One. 2009:4:e7936.

13. Majumder S. REST in good times and bad: roles in tumor suppressor and oncogenic activities. Cell Cycle. 2006;5:1929-35.

14. Chong JA, Tapia-Ramirez J, Kim S, Toledo-Aral JJ, Zheng Y, Boutros MC, Altshuller YM, Frohman MA, Kraner SD, Mandel G. REST: a mammalian silencer protein that restricts sodium channel gene expression to neurons. Cell. 1995:80:949-57.

15. Schoenherr CJ, Anderson DJ. The neuron-restrictive silencer factor (NRSF): a coordinate repressor of multiple neuron-specific genes. Science. 1995;267:1360-3.

16. Das CM, Taylor P, Gireud M, Singh A, Lee D, Fuller G, Ji L, Fangusaro J, Rajaram V, Goldman S, et al. The deubiquitylase USP37 links REST to the control of p27 stability and cell proliferation. Oncogene. 2013;32:1691-701.

17. Fuller GN, Su X, Price RE, Cohen ZR, Lang FF, Sawaya R, Majumder S. Many human medulloblastoma tumors overexpress repressor element-1 silencing transcription (REST)/neuron-restrictive silencer factor, which can be functionally countered by REST-VP16. Mol Cancer Ther. 2005;4:343-9.

18. Lawinger P, Venugopal R, Guo ZS, Immaneni A, Sengupta D, Lu W, Rastelli L, Marin Dias Carneiro A, Levin V, Fuller GN, et al. The neuronal repressor REST/NRSF is an essential regulator in medulloblastoma cells. Nat Med. 2000;6:826-31.

19. Taylor P, Fangusaro J, Rajaram V, Goldman S, Helenowski IB, MacDonald T, Hasselblatt M, Riedemann L, Laureano A, Cooper L, Gopalakrishnan V. REST is a novel prognostic factor and therapeutic target for medulloblastoma. Mol Cancer Ther. 2012;11:1713-23.
20. Su X, Gopalakrishnan V, Stearns D, Aldape K, Lang FF, Fuller G, Snyder E, Eberhart CG, Majumder S. Abnormal expression of REST/NRSF and Myc in neural stem/progenitor cells causes cerebellar tumors by blocking neuronal differentiation. Mol Cell Biol. 2006;26:1666-78.

21. Dobson THW, Hatcher RJ, Swaminathan J, Das CM, Shaik S, Tao RH, Milite C, Castellano S, Taylor PH, Sbardella G, Gopalakrishnan V. Regulation of USP37 expression by REST-associated G9a-dependent histone methylation. Mol Cancer Res. 2017;15:1073-84.

22. Du T, Zhou G, Khan S, Gu H, Roizman B. Disruption of HDAC/CoREST/REST repressor by dnREST reduces genome silencing and increases virulence of herpes simplex virus. Proc Natl Acad Sci U S A. 2010;107:15904-9.

23. Singh MM, Johnson B, Venkatarayan A, Flores ER, Zhang J, Su X, Barton M, Lang F, Chandra J. Preclinical activity of combined HDAC and KDM1A inhibition in glioblastoma. Neuro-Oncology. 2015;17:1463-73.

24. Shi YJ, Matson C, Lan F, Iwase S, Baba T, Shi Y. Regulation of LSD1 histone demethylase activity by its associated factors. Mol Cell. 2005;19:857-64.

25. Culhane JC, Cole PA. LSD1 and the chemistry of histone demethylation. Curr Opin Chem Biol. 2007;11:561-8.

26. Lee JY, Park JH, Choi HJ, Won HY, Joo HS, Shin DH, Park MK, Han B, Kim KP, Lee TJ, et al. LSD1 demethylates HIF1alpha to inhibit hydroxylation and ubiquitin-mediated degradation in tumor angiogenesis. Oncogene. 2017;36:5512-21.

27. Paitler KW, Weingarten C, Thor T, Kunkele A, Heukamp LC, Buttner R, Suzuki T, Miyata N, Grotzer M, Rieb A, et al. The KDM1A histone demethylase is a promising new target for the epigenetic therapy of medulloblastoma. Acta Neuropathol Commun. 2013;1:19.

28. Dubuc AM, Remke M, Korshunov A, Northcott PA, Zhan SH, Mendez-Lago M, Kool M, Jones DT, Unterberger A, Morrissy AS, et al. Aberrant patterns of H3K4 and H3K27 histone lysine methylation occur across subgroups in medulloblastoma. Acta Neuropathol. 2013:125:373-84

29. Joseph JV, Conroy S, Pavlov K, Sontakke P, Tomar T, Eggens-Meijer E, Balasubramaniyan V, Wagemakers M, den Dunnen WF, Kruyt FA. Hypoxia enhances migration and invasion in glioblastoma by promoting a mesenchymal shift mediated by the HIF1alpha-ZEB1 axis. Cancer Lett. 2015;359:107-16.

30. Mendez O, Zavadil J, Esencay M, Lukyanov Y, Santovasi D, Wang SC, Newcomb EW, Zagzag D. Knock down of HIF-1alpha in glioma cells reduces migration in vitro and invasion in vivo and impairs their ability to form tumor spheres. Mol Cancer. 2010;9:133.

31. Kageyama Y, Koshiji M, To KK, Tian YM, Ratcliffe PJ, Huang LE. Leu-574 of human HIF-1alpha is a molecular determinant of prolyl hydroxylation. FASEB J. 2004;18:1028-30.

32. Sun G, Alzayady K, Stewart R, Ye P, Yang S, Li W, Shi Y. Histone demethylase LSD1 regulates neural stem cell proliferation. Mol Cell Biol. 2010;30:1997-2005.

33. Toffolo E, Rusconi F, Paganini L, Tortorici M, Pilotto S, Heise C, Verpelli C, Tedeschi G, Maffioli E, Sala C, et al. Phosphorylation of neuronal lysinespecific demethylase 1LSD1/KDM1A impairs transcriptional repression by regulating interaction with COREST and histone deacetylases HDAC1/2. J Neurochem. 2014;128:603-16.

34. Lynch JT, Harris WJ, Somervaille TC. LSD1 inhibition: a therapeutic strategy in cancer? Expert Opin Ther Targets. 2012;16:1239-49.

35. Kim Y, Nam HJ, Lee J, Park DY, Kim C, Yu YS, Kim D, Park SW, Bhin J, Hwang $D$, et al. Methylation-dependent regulation of HIF-1alpha stability restricts retinal and tumour angiogenesis. Nat Commun. 2016;7:10347.

36. Cavadas MA, Mesnieres M, Crifo B, Manresa MC, Selfridge AC, Scholz CC, Cummins EP, Cheong A, Taylor CT. REST mediates resolution of HIFdependent gene expression in prolonged hypoxia. Sci Rep. 2015;5:17851.

37. Baek SH, Kim Kl. Regulation of HIF-1alpha stability by lysine methylation. BMB Rep. 2016:49:245-6

38. Lee MG, Wynder C, Cooch N, Shiekhattar R. An essential role for CoREST in nucleosomal histone 3 lysine 4 demethylation. Nature. 2005:437:432-5.

39. Shi Y, Lan F, Matson C, Mulligan P, Whetstine JR, Cole PA, Casero RA, Shi Y. Histone demethylation mediated by the nuclear amine oxidase homolog LSD1. Cell. 2004;119:941-53.

40. Wang $Y$, Zhang $H$, Chen $Y$, Sun Y, Yang F, Yu W, Liang J, Sun L, Yang X, Shi $L$, et al. LSD1 is a subunit of the NuRD complex and targets the metastasis programs in breast cancer. Cell. 2009;138:660-72.

41. Metzger E, Wissmann M, Yin N, Muller JM, Schneider R, Peters AH, Gunther T, Buettner R, Schule R. LSD1 demethylates repressive histone marks to promote androgen-receptor-dependent transcription. Nature. 2005:437:436-9. 
42. Ballas N, Battaglioli E, Atouf F, Andres ME, Chenoweth J, Anderson ME, Burger C, Moniwa M, Davie JR, Bowers WJ, et al. Regulation of neuronal traits by a novel transcriptional complex. Neuron. 2001;31:353-65.

43. Foster CT, Dovey OM, Lezina L, Luo JL, Gant TW, Barlev N, Bradley A, Cowley SM. Lysine-specific demethylase 1 regulates the embryonic transcriptome and CoREST stability. Mol Cell Biol. 2010;30:4851-63.

44. Mohammad HP, Smitheman KN, Kamat CD, Soong D, Federowicz KE, Van Aller GS, Schneck JL, Carson JD, Liu Y, Butticello M, et al. A DNA Hypomethylation signature predicts antitumor activity of LSD1 inhibitors in SCLC. Cancer Cell. 2015;28:57-69.

45. Yi L, Cui Y, Xu Q, Jiang Y. Stabilization of LSD1 by deubiquitinating enzyme USP7 promotes glioblastoma cell tumorigenesis and metastasis through suppression of the p53 signaling pathway. Oncol Rep. 2016;36:2935-45.

46. Huang Z, Wu Q, Guryanova OA, Cheng L, Shou W, Rich JN, Bao S. Deubiquitylase HAUSP stabilizes REST and promotes maintenance of neural progenitor cells. Nat Cell Biol. 2011;13:142-52.

47. Gupta S, Doyle K, Mosbruger TL, Butterfield A, Weston A, Ast A, Kaadige M, Verma A, Sharma S. Reversible LSD1 inhibition with HCl-2509 induces the p53 gene expression signature and disrupts the MYCN signature in high-risk neuroblastoma cells. Oncotarget. 2018;9:9907-24.

48. Westbrook TF, Hu G, Ang XL, Mulligan P, Pavlova NN, Liang A, Leng Y, Maehr R, Shi Y, Harper JW, Elledge SJ. SCFbeta-TRCP controls oncogenic transformation and neural differentiation through REST degradation. Nature. 2008:452:370-4

49. Brandes AA, Bartolotti M, Marucci G, Ghimenton C, Agati R, Fioravanti A, Mascarin M, Volpin L, Ammannati F, Masotto B, et al. New perspectives in the treatment of adult medulloblastoma in the era of molecular oncology. Crit Rev Oncol Hematol. 2015;94:348-59.

50. Brandes AA, Franceschi E. Shedding light on adult medulloblastoma: current management and opportunities for advances. Am Soc Clin Oncol Educ Book. 2014:e82-7. (Print ISSN: 1548-8748; Electronic ISSN: 1548-8756).

51. Lindsey JC, Schwalbe EC, Potluri S, Bailey S, Williamson D, Clifford SC. TERT promoter mutation and aberrant hypermethylation are associated with elevated expression in medulloblastoma and characterise the majority of non-infant SHH subgroup tumours. Acta Neuropathol. 2014;127:307-9.

52. Castelo-Branco P, Choufani S, Mack S, Gallagher D, Zhang C, Lipman T, Zhukova N, Walker EJ, Martin D, Merino D, et al. Methylation of the TERT promoter and risk stratification of childhood brain tumours: an integrative genomic and molecular study. Lancet Oncol. 2013;14:534-42.

53. Killela PJ, Reitman ZJ, Jiao Y, Bettegowda C, Agrawal N, Diaz LA Jr, Friedman AH, Friedman H, Gallia GL, Giovanella BC, et al. TERT promoter mutations occur frequently in gliomas and a subset of tumors derived from cells with low rates of self-renewal. Proc Natl Acad Sci U S A. 2013;110:6021-6.

54. Saha D, Singh A, Hussain T, Srivastava V, Sengupta S, Kar A, Dhapola P, Dhople V, Ummanni R, Chowdhury S. Epigenetic suppression of human telomerase (hTERT) is mediated by the metastasis suppressor NME2 in a Gquadruplex-dependent fashion. J Biol Chem. 2017;292:15205-15.

55. Zhu Q, Liu C, Ge Z, Fang X, Zhang X, Straat K, Bjorkholm M, Xu D. Lysine-specific demethylase 1 (LSD1) is required for the transcriptional repression of the telomerase reverse transcriptase (hTERT) gene. PLoS One. 2008;3:e1446.

56. Mould DP, McGonagle AE, Wiseman DH, Williams EL, Jordan AM. Reversible inhibitors of LSD1 as therapeutic agents in acute myeloid leukemia: clinical significance and progress to date. Med Res Rev. 2015;35:586-618.

57. Schulz-Fincke J, Hau M, Barth J, Robaa D, Willmann D, Kurner A, Haas J, Greve G, Haydn T, Fulda S, et al. Structure-activity studies on N-substituted tranylcypromine derivatives lead to selective inhibitors of lysine specific demethylase 1 (LSD1) and potent inducers of leukemic cell differentiation. Eur J Med Chem. 2018:144:52-67.

58. Zheng YC, Yu B, Jiang GZ, Feng XJ, He PX, Chu XY, Zhao W, Liu HM. Irreversible LSD1 inhibitors: application of tranylcypromine and its derivatives in Cancer treatment. Curr Top Med Chem. 2016;16:2179-88.

Ready to submit your research? Choose BMC and benefit from:

- fast, convenient online submission

- thorough peer review by experienced researchers in your field

- rapid publication on acceptance

- support for research data, including large and complex data types

- gold Open Access which fosters wider collaboration and increased citations

- maximum visibility for your research: over $100 \mathrm{M}$ website views per year

At BMC, research is always in progress.

Learn more biomedcentral.com/submissions 